\title{
Mid-L/D Lifting Body Entry Demise Analysis
}

\author{
Dr. Lisa Ling ${ }^{1}$ \\ NASA Johnson Space Center, Houston, TX, 77058
}

The mid-lift-to-drag ratio (mid-L/D) lifting body is a fully autonomous spacecraft under design at NASA for enabling a rapid return of scientific payloads from the International Space Station (ISS). For contingency planning and risk assessment for the Earth-return trajectory, an entry demise analysis was performed to examine three potential failure scenarios: (1) nominal entry interface conditions with loss of control, (2) controlled entry at maximum flight path angle, and (3) controlled entry at minimum flight path angle. The objectives of the analysis were to predict the spacecraft breakup sequence and timeline, determine debris survival, and calculate the debris dispersion footprint. Sensitivity analysis was also performed to determine the effect of the initial pitch rate on the spacecraft stability and breakup during the entry. This report describes the mid-L/D lifting body and presents the results of the entry demise and sensitivity analyses.

$\begin{array}{ll}\mathrm{Al} & =\text { aluminum } \\ \alpha & =\text { angle-of-attack } \\ \mathrm{BMI} & =\text { bismaleimide } \\ \mathrm{C}_{\mathrm{A}} & =\text { axial force coefficient } \\ \mathrm{C}_{\mathrm{l}} & =\text { roll moment coefficient } \\ \mathrm{C}_{\mathrm{lp}} & =\text { roll damping coefficient } \\ \mathrm{C}_{\mathrm{m}} & =\text { pitch moment coefficient } \\ \mathrm{C}_{\mathrm{mq}} & =\text { pitch damping coefficient } \\ \mathrm{C}_{\mathrm{N}} & =\text { normal force coefficient } \\ \mathrm{C}_{\mathrm{n}} & =\text { yaw moment coefficient } \\ \mathrm{C}_{\mathrm{nr}} & =\text { yaw damping coefficient } \\ \mathrm{C}_{\mathrm{Y}} & =\text { side force coefficient } \\ \gamma & =\text { flight path angle } \\ \mathrm{I}_{\mathrm{xx}}, \mathrm{I}_{\mathrm{yy}}, \mathrm{I}_{\mathrm{zz}} & =\text { moments of inertia } \\ \mathrm{I}_{\mathrm{xy}}, \mathrm{I}_{\mathrm{xz}}, \mathrm{I}_{\mathrm{yz}} & =\text { products of inertia } \\ & \end{array}$

\section{Nomenclature}

I. Introduction

$\mathrm{T}$ HE mid-L/D lifting body is a fully autonomous spacecraft under design at NASA for enabling a rapid return of scientific payloads from the International Space Station (ISS). For contingency planning and risk assessment for the Earth-return trajectory, an entry demise analysis was performed to examine three potential failure scenarios resulting in off-nominal atmospheric entry: (1) nominal entry interface conditions with loss of control, (2) controlled entry at maximum flight path angle, and (3) controlled entry at minimum flight path angle. The objectives of the analysis were to predict the spacecraft breakup sequence and timeline, determine debris survival, and calculate the debris dispersion footprint. Sensitivity analysis was also performed to determine the effect of the initial pitch rate on the spacecraft stability and breakup during the entry. This report describes the mid-L/D lifting body and presents the results of the entry demise and sensitivity analyses.

Six degrees-of-freedom trajectory simulations were performed using the Simulation for Prediction of Entry Article Demise (SPEAD) software tool [1]. Heating models for convective, conductive, and radiative heat transfers were embedded in the software for thermal analysis. In a nominal entry, the spacecraft flies a predominantly lift-up

\footnotetext{
${ }^{1}$ Flight Mechanics Technical Discipline Lead, Aeroscience \& Flight Mechanics Division, 2101 NASA Road One, Houston, TX 77058/EG5.
} 
trajectory and modulates the magnitude and direction of the bank angle for targeting. The target landing site is the Vandenberg Air Force Base located on the coast of California.

\section{Reentry Scenarios}

The initial conditions at entry interface (EI) for the three entry scenarios are given in Table 1. For the first failure scenario, the initial condition of the nominal trajectory was used for the propagation of the uncontrolled trajectory in SPEAD. An initial pitch rate of $10 \mathrm{deg} / \mathrm{s}$ was assumed. For the second and third failure scenarios, the complete trajectories for the controlled entries were used in the analysis in lieu of propagation with closed-loop guidance, navigation, and control $(\mathrm{GN} \& \mathrm{C})$ in SPEAD. This avoided the need to implement the GN\&C models into the SPEAD software. The vehicle entered the atmosphere from a posigrade orbit towards the descending node.

Table 1. Initial Conditions

\begin{tabular}{|l|c|c|c|}
\hline \multicolumn{1}{|c|}{ Variable } & Nominal & Max $\boldsymbol{\gamma}_{\mathbf{E I}}$ & Min $\boldsymbol{\gamma}_{\mathbf{E I}}$ \\
\hline Altitude $(\mathrm{km})$ & 124.86 & 124.99 & 124.91 \\
\hline Latitude $(\mathrm{deg})$ & 51.6423 & 51.6229 & 51.7028 \\
\hline Longitude (deg) & -169.5064 & -169.1425 & -171.2690 \\
\hline Speed $(\mathrm{m} / \mathrm{s})$ & 7602.90 & 7603.11 & 7602.16 \\
\hline Flight path angle (deg) & -1.1470 & -1.1400 & -1.1696 \\
\hline Azimuth angle (deg) & 94.0753 & 94.3829 & 92.5802 \\
\hline Angle-of-attack (deg) & 55.2632 & 55.7194 & 64.1907 \\
\hline Sideslip angle (deg) & -4.1424 & 2.3810 & -1.0210 \\
\hline Bank angle (deg) & 72.6816 & 65.9626 & 72.4778 \\
\hline
\end{tabular}

\section{Vehicle Properties}

The outer mold line of the vehicle is protected from aeroheating by a thermal protection system (TPS) consisting of LI2000 tiles and FRSI. The majority of the top side and the aft end are covered by Felt Reusable Surface Insulation (FRSI), and the remainder of the vehicle is shielded by LI2000 tiles as shown in Figure 1. The TPS is bonded to the substrate via strain/isolator pad (SIP) or room temperature vulcanizing (RTV) silicon adhesive. The major components in the interior of the vehicle consist of structural supports, two cylindrical argon propellant tanks, main engine, cold gas (argon) attitude control thrusters, payload or ballast, landing recovery systems, and GN\&C and avionics subsystems.

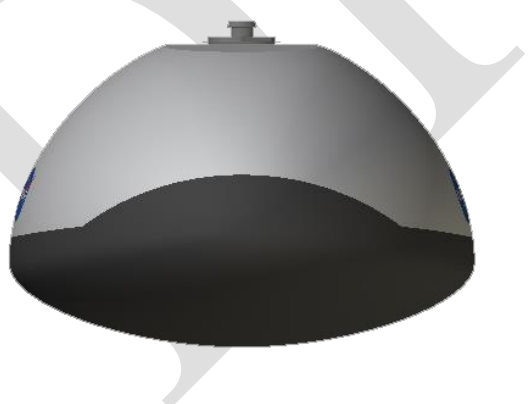

(a) Front View

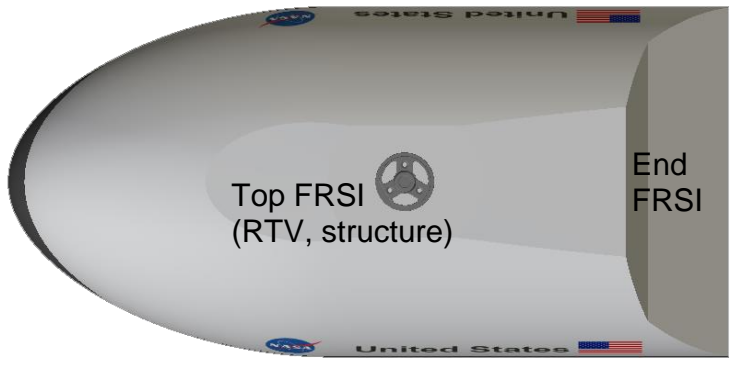

(b) Top View 


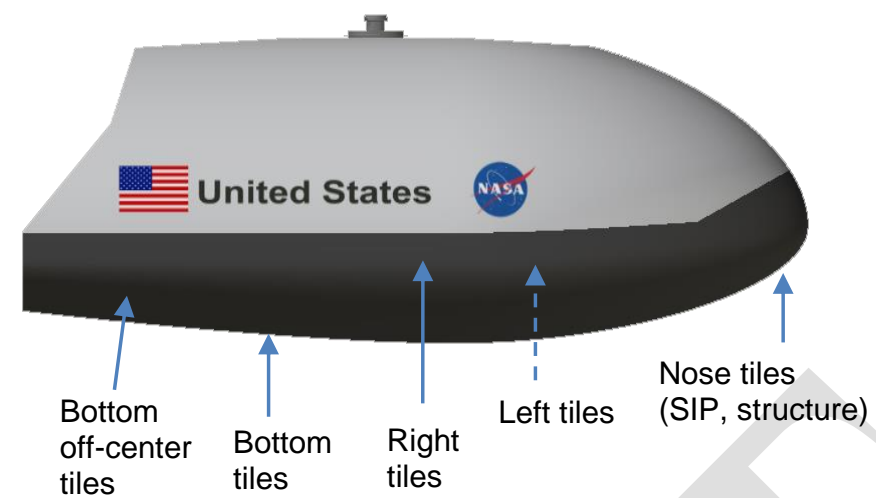

(c) Side View

Figure 1. Thermal Nodes

\section{A. Aerodynamic Properties}

Hypersonic aerodynamics based on Newtonian theory was used for the analysis, which characterized the vehicle as bi-stable. The first trim angle-of-attack $(\alpha)$ is near 60 degrees in the nose-up, heatshield-forward orientation, while the second is nose-down with FRSI-forward. The axial, side, and normal force coefficients $\left(\mathrm{C}_{\mathrm{A}}, \mathrm{C}_{\mathrm{Y}}, \mathrm{C}_{\mathrm{N}}\right)$ and the roll, pitch, and yaw moment coefficients $\left(\mathrm{C}_{1}, \mathrm{C}_{\mathrm{m}}, \mathrm{C}_{\mathrm{n}}\right)$ for the intact vehicle are provided in Figure 2. Zero offset of the center-of-gravity (c.g.) from the pitch plane of the spacecraft is assumed.

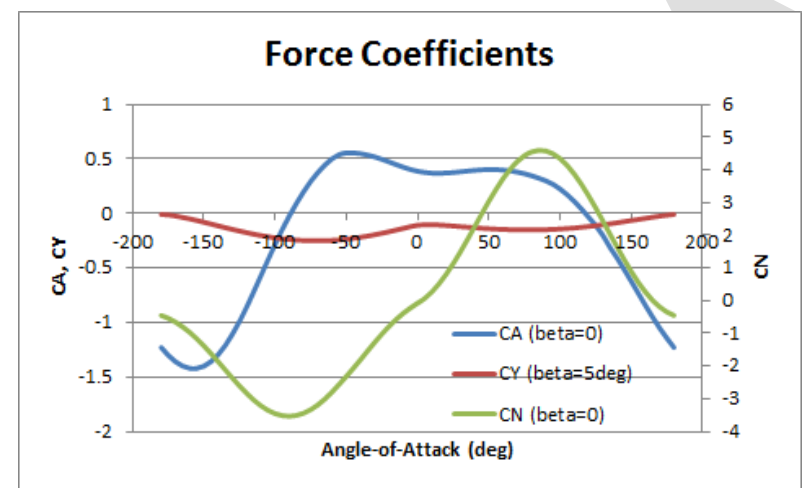

(a) Force Coefficients

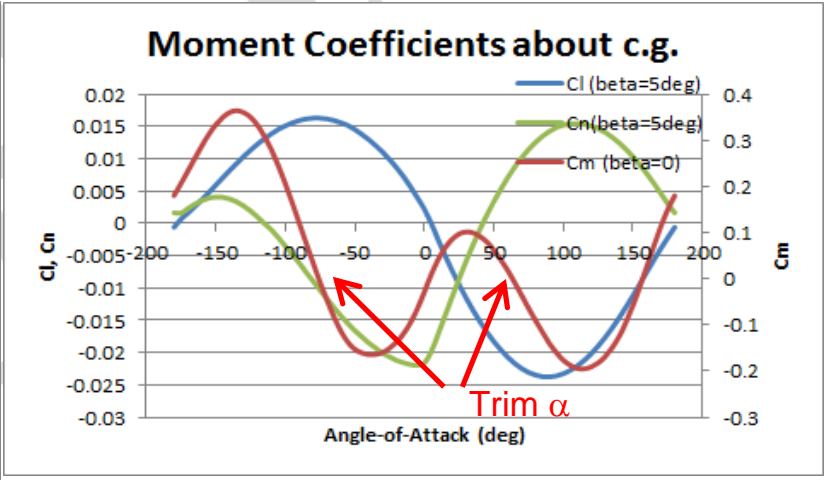

(b) Moment Coefficients

Figure 2. Aerodynamic Coefficients

The aerodynamic reference area is $0.23175 \mathrm{~m}^{2}$, and the reference length is $124.46 \mathrm{~cm}$. The assumed aerodynamic damping coefficients are:

$$
\begin{aligned}
& \mathrm{C}_{\mathrm{lp}}=-0.4 \mathrm{rad}^{-1} \\
& \mathrm{C}_{\mathrm{mq}}=-0.6 \mathrm{rad}^{-1} \\
& \mathrm{C}_{\mathrm{nr}}=-0.6 \mathrm{rad}^{-1}
\end{aligned}
$$

Note that the aerodynamic coefficients for the main vehicle were not updated during the breakup of the vehicle. Once a component separated from the vehicle, it was assumed to tumble, and the component's mass and aerodynamic properties were updated as the simulation switched seamlessly to 3-DOF trajectory propagation for the individual component.

\section{B. Mass Properties}

The mass properties of the vehicle at EI are provided below: 
Vehicle total mass $=84.16 \mathrm{~kg}$

$\mathrm{I}_{\mathrm{xx}}=2.3033 \mathrm{~kg}-\mathrm{m}^{2}$

$\mathrm{I}_{\mathrm{yy}}=9.1845 \mathrm{~kg}-\mathrm{m}^{2}$

$\mathrm{I}_{\mathrm{zz}}=10.2998 \mathrm{~kg}-\mathrm{m}^{2}$

$\mathrm{I}_{\mathrm{xy}}=0.0 \mathrm{~kg}-\mathrm{m}^{2}$

$\mathrm{I}_{\mathrm{xz}}=-0.0021 \mathrm{~kg}-\mathrm{m}^{2}$

$\mathrm{I}_{\mathrm{yz}}=0.0 \mathrm{~kg}-\mathrm{m}^{2}$

A mass of $3 \mathrm{~kg}$ for the argon propellant was assumed. The mass, inertia tensor, and c.g. location were updated during the breakup analysis.

\section{Thermal Nodes}

Thirty-two thermal nodes were modeled for the mid-L/D lifting body, consisting of components from the tiles, FRSI, substrate, structure, tanks, and main jet. The node material types are provided in Table 2.

Table 2. Thermal Node Material Type

\begin{tabular}{|l|c|}
\hline \multicolumn{1}{|c|}{ Node } & Material \\
\hline FRSI & FRSI \\
\hline RTV & RTV560 \\
\hline Structure & Carbon BMI \\
\hline Nose tile & LI2200 \\
\hline Right / left tile & LI2200 \\
\hline Bottom tile & LI2200 \\
\hline Off-center tile & LI2200 \\
\hline SIP & RTV560 \\
\hline Tank glass epoxy & Glass epoxy \\
\hline Tank carbon epoxy & Carbon epoxy \\
\hline Tank Al & Al 6061 \\
\hline Front tank support & Carbon BMI \\
\hline Aft tank support & Carbon BMI \\
\hline Forward support & Carbon BMI \\
\hline Main engine & Inconel \\
\hline
\end{tabular}

Ablation properties for the LI2200 and FRSI were obtained from Ref. [2] and [3]. The initial temperature of all nodes was assumed $273 \mathrm{~K}$. One-dimensional conductive heat transfer was modeled for the FRSI-RTV-structure; LI2200-SIP-structure; and tank layers. The tanks were assumed to be released when both the front and aft supports failed. During ablation, changes in the node mass, dimensions, and areas were simulated. Note that the outcome of the ballast or payload was not evaluated due to lack of characteristics data.

\section{Results}

The trajectory plots for the uncontrolled nominal entry for failure scenario 1 are provided in Figure 3.

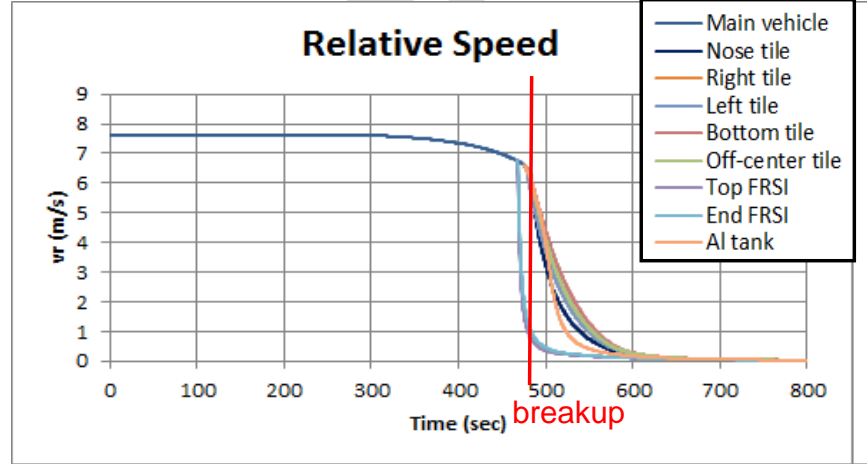

(a) Relative Speed

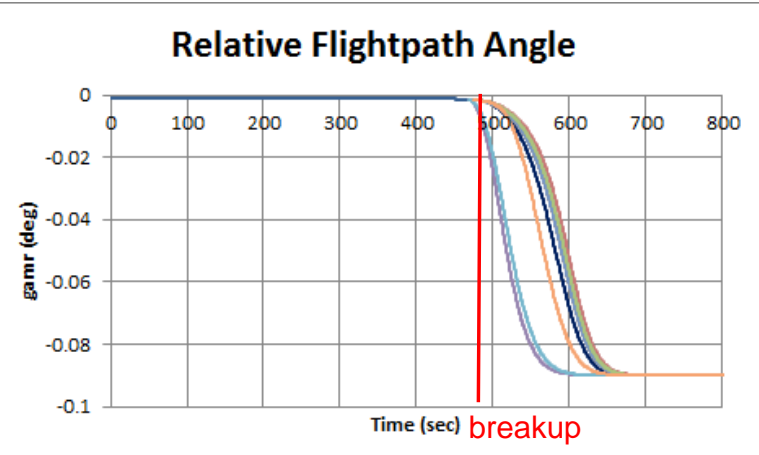

(b) Relative Flight Path Angle

American Institute of Aeronautics and Astronautics 


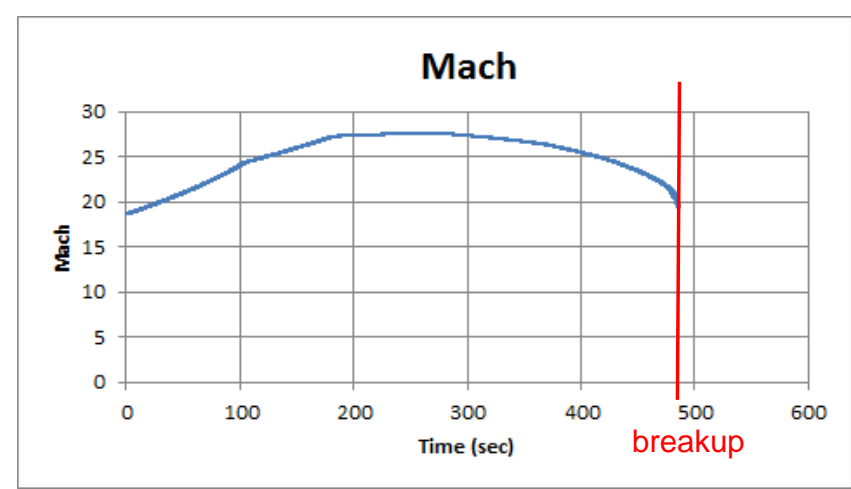

(c) Mach

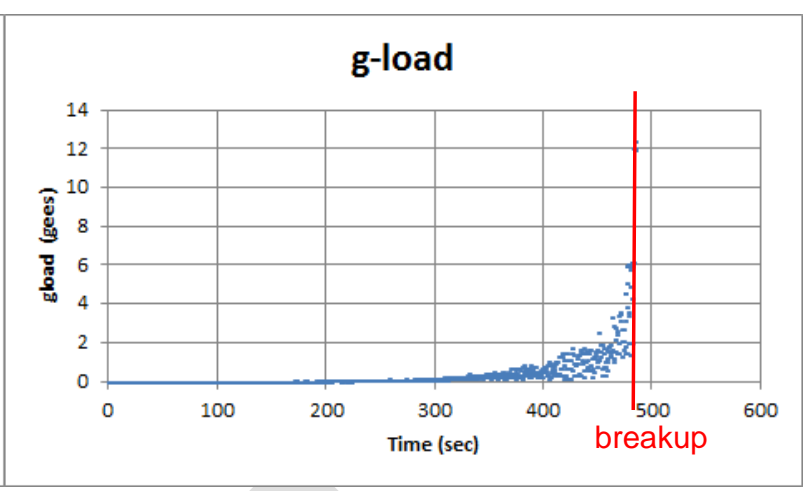

(d) g-load

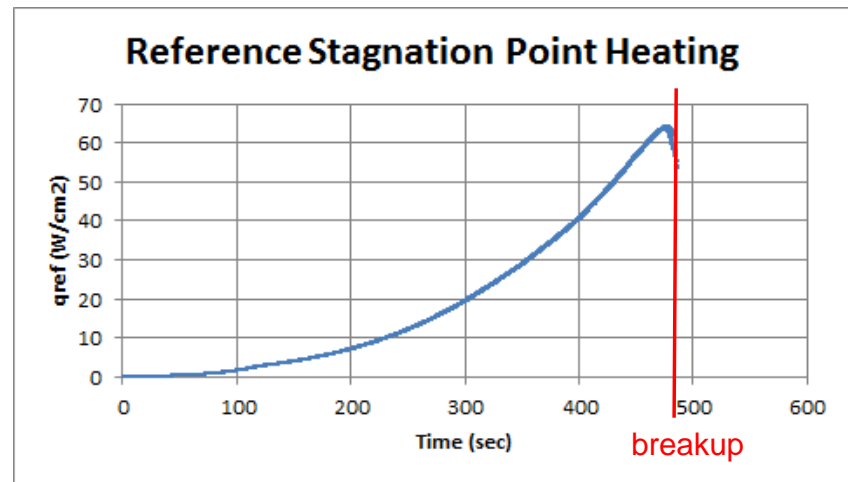

(e) Reference Stagnation Point Heating

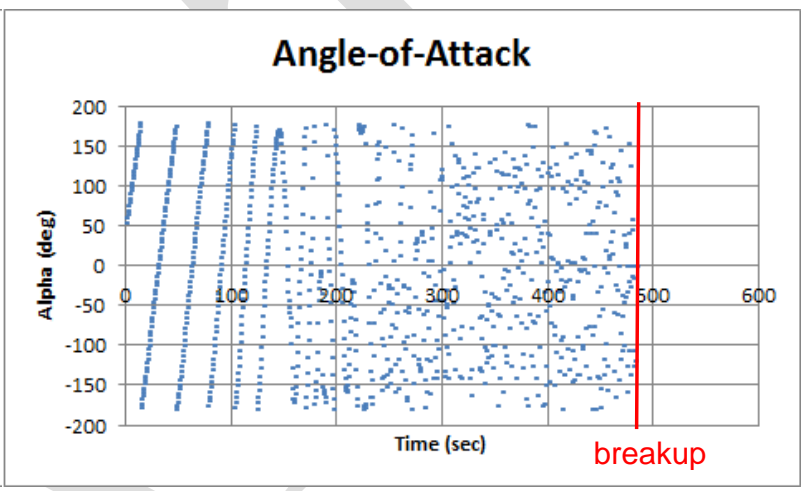

(f) Angle-of-Attack

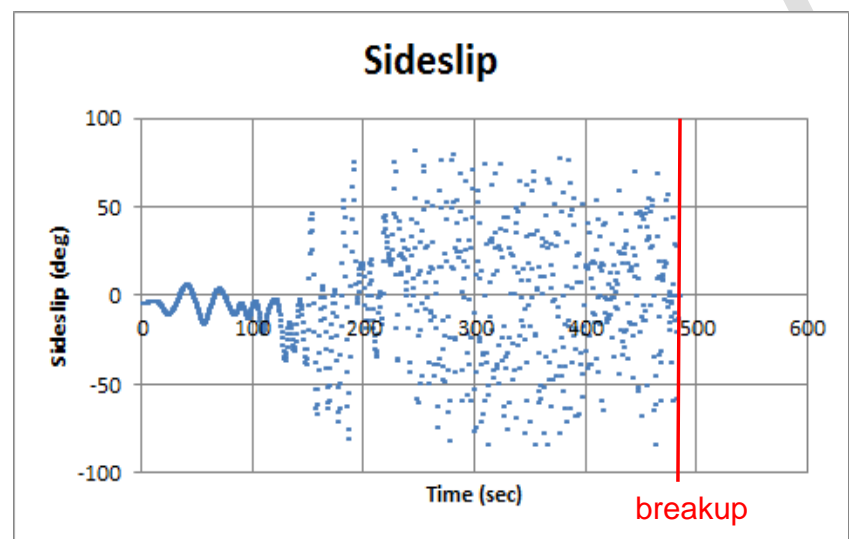

(g) Sideslip Angle

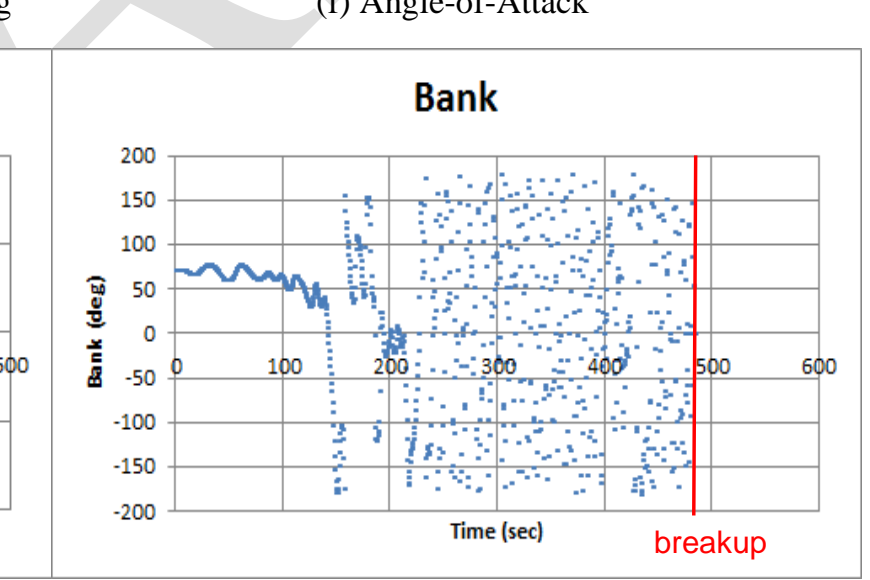

(h) Bank Angle

Figure 3. Trajectory Plots for Failure Scenario One

At an initial pitch rate of $10 \mathrm{deg} / \mathrm{s}$, the vehicle remained tumbling during the entry, subjecting the FRSI to direct aeroheating. The sequence of the vehicle breakup began with the failure of the top structure and subsequently the end structure from conductive heating through the FRSI. The breach led to the exposure of the interior nodes to aeroheating. Next, the right aft tank support failed, and the left aft tank support followed suit. Thereafter, the front tank support failed, releasing the tanks. The structure of the vehicle began failing, releasing the left tiles and the right tiles. The forward support failed next, and once the bottom off-center structure failed, the vehicle was assumed to break up, releasing the nose and bottom tiles and the main engine. The breakup altitude was $64.37 \mathrm{~km}$. The tanks burst due to excessive internal pressure at $64.2 \mathrm{~km}$. The breakup timeline and altitude traces are illustrated in Figure 4. 


\section{Breakup Timeline}

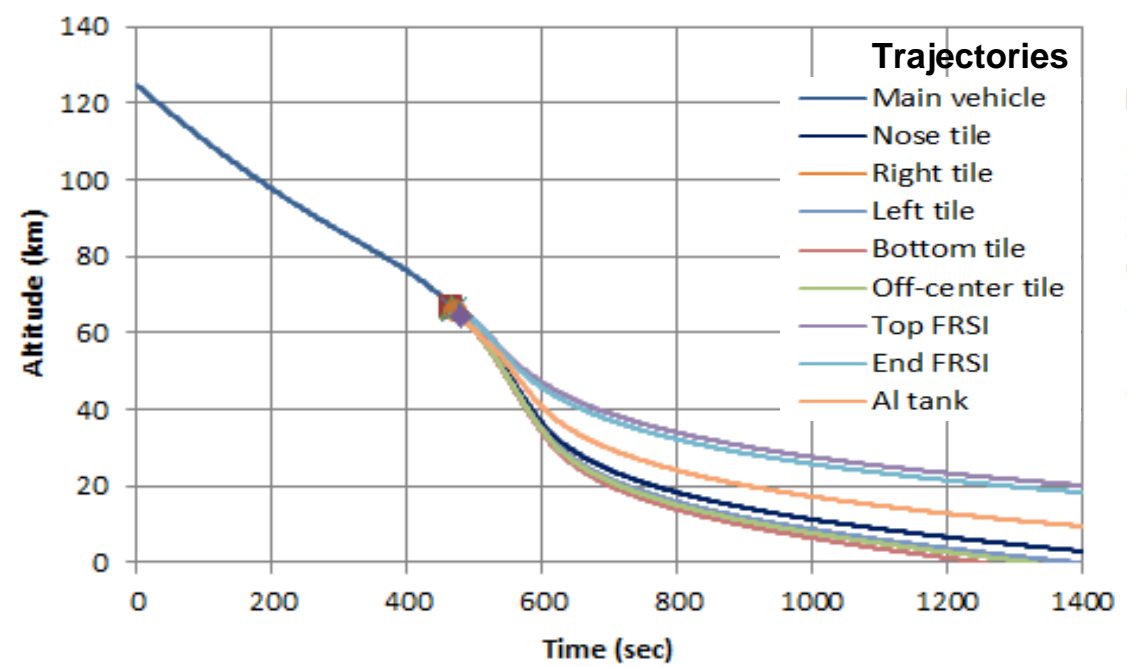

Node Failure

Top structure

$\Delta$ End structure

$\times$ Right aft tank support

* Left aft tank support

- Front tank support

+ Left structure

- Right structure

- Forward support

- Bottom off-center structure

Figure 4. Breakup Timeline for Failure Scenario One

Most of the non-TPS components burned up during the entry. The surviving debris included the heatshield tiles, FRSI fragments, and aluminum tank fragments. The lift-down portions of the trajectory produced by the tumbling motion of the vehicle during the entry led to a decrease in the downrange distance. Thus, all of the surviving debris impacted the Pacific Ocean. The mass of the surviving debris and their impact points are provided in Table 3.

Table 3. Surviving Debris Mass and Impact Points for Failure Scenario One

\begin{tabular}{|l|c|c|c|}
\hline \multicolumn{1}{|c|}{ Debris } & Mass (kg) & $\begin{array}{c}\text { Geocentric } \\
\text { latitude (deg) }\end{array}$ & Longitude (deg) \\
\hline Nose tiles & 0.5433 & 38.1873 & -124.9555 \\
\hline Right tiles & 0.4671 & 38.0132 & -124.6925 \\
\hline Left tiles & 0.4662 & 38.0142 & -124.6940 \\
\hline Bottom tiles & 0.6909 & 37.7385 & -124.2801 \\
\hline Bottom off-center tiles & 0.6576 & 37.8630 & -124.4658 \\
\hline Top FRSI fragment & 0.34 & 39.4561 & -126.9552 \\
\hline End FRSI fragment & 0.13 & 39.3851 & -126.8397 \\
\hline Al tank fragment & 0.5112 & 38.2639 & -125.0701 \\
\hline
\end{tabular}

The one-sigma debris footprint for failure scenario 1 is:

Semi-major axis $=110.5 \mathrm{~km}$

Semi-minor axis $=0.5 \mathrm{~km}$

Azimuth $=129.2 \mathrm{deg}$

The ground track on a world map is given in Figure 5. 


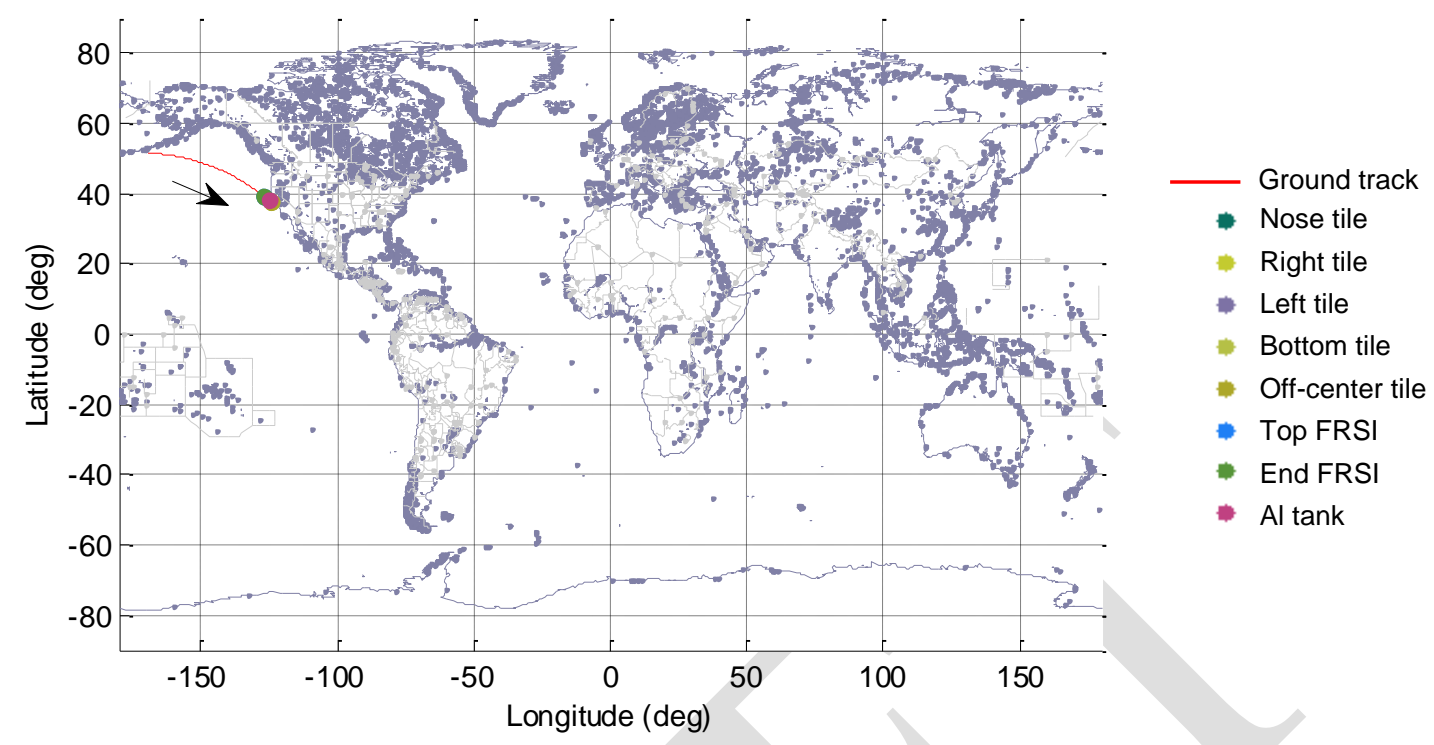

Figure 5. Ground Track on World Map for Failure Scenario One

The close-up illustration of the debris impact points is given on a Google Map in Figure 6.

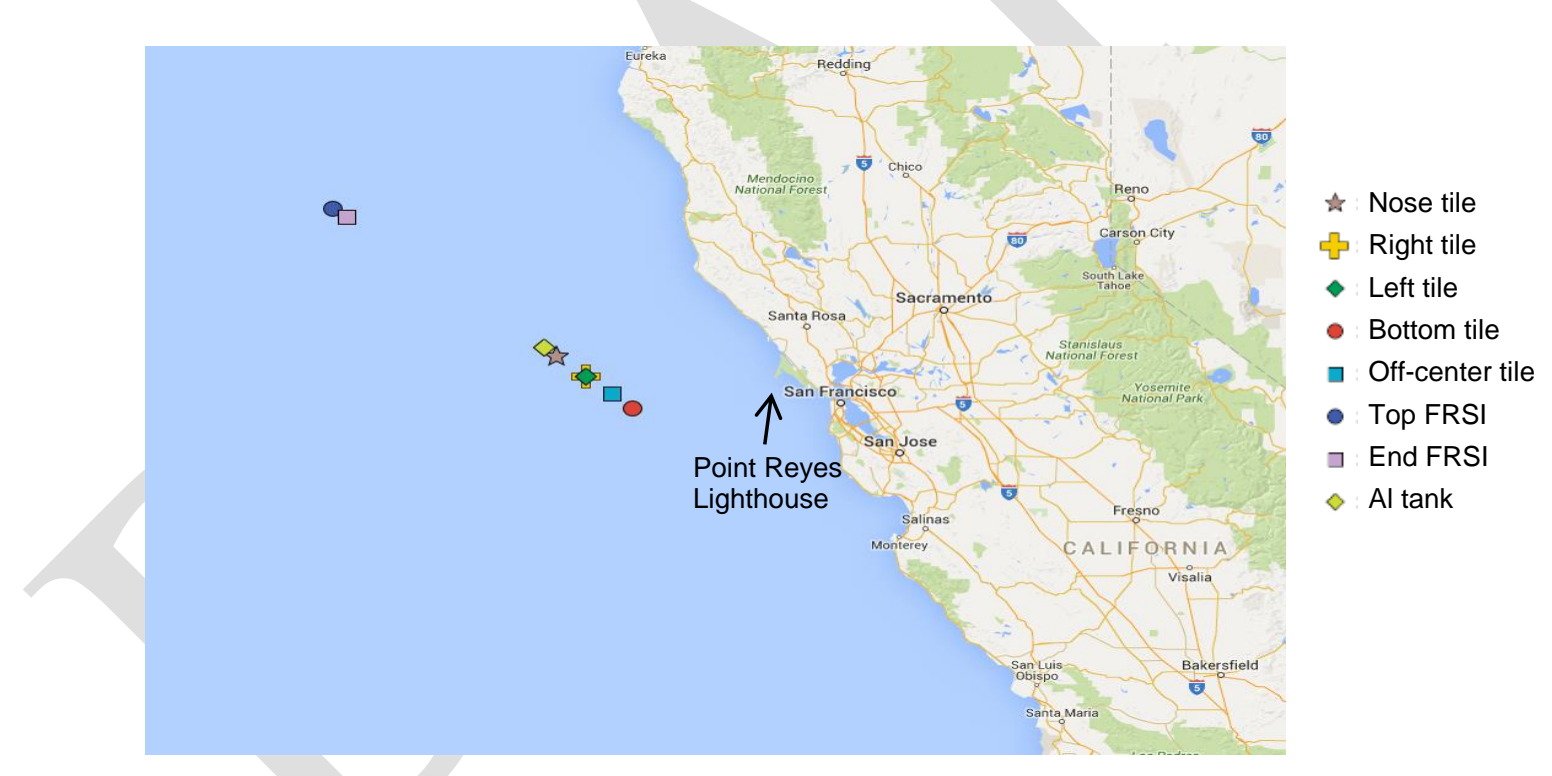

Figure 6. Debris Impact Points for Failure Scenario One

For failure scenarios 2 and 3, the vehicle remained in the heatshield-forward orientation during the controlled entry and did not break up. The attitude plots for these two failure scenarios are provided in Figure 7 - Figure 8. 


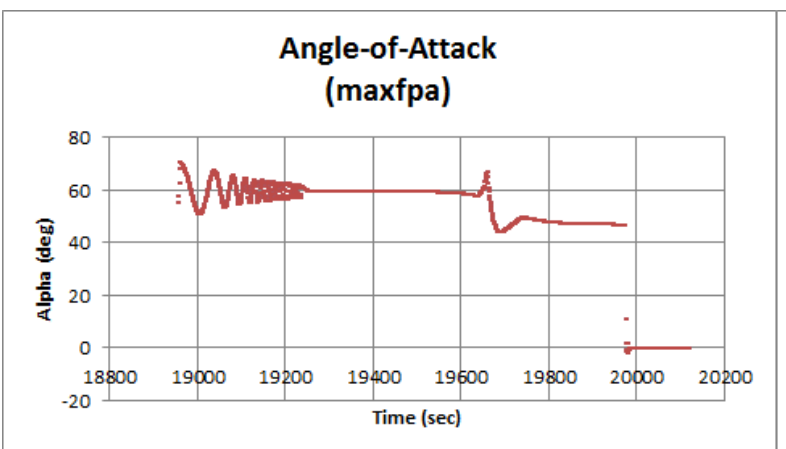

(a) Angle-of-Attack

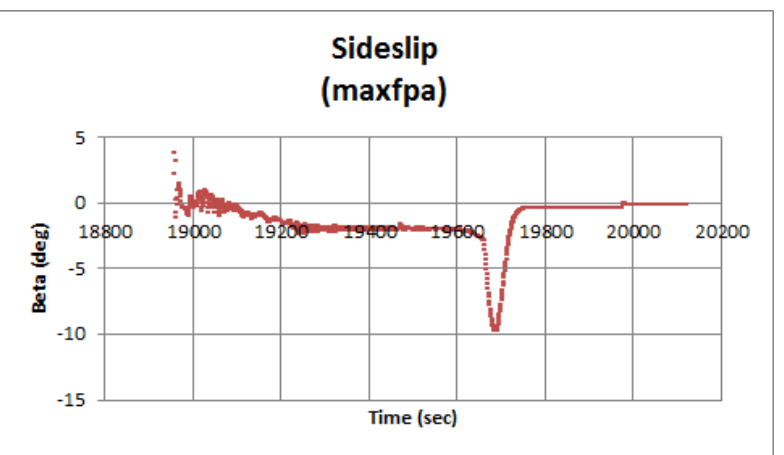

(b) Sideslip Angle

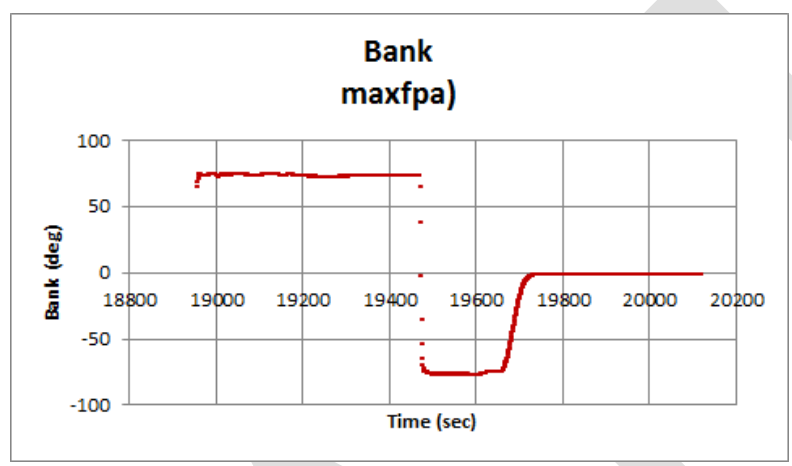

(c) Bank Angle

Figure 7. Attitude Plots for Failure Scenario Two (Max $\left.\gamma_{\mathrm{EI}}\right)$

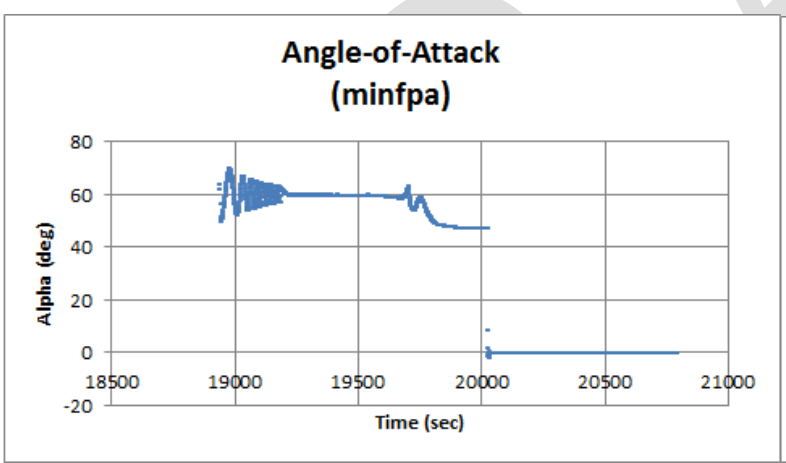

(a) Angle-of-Attack

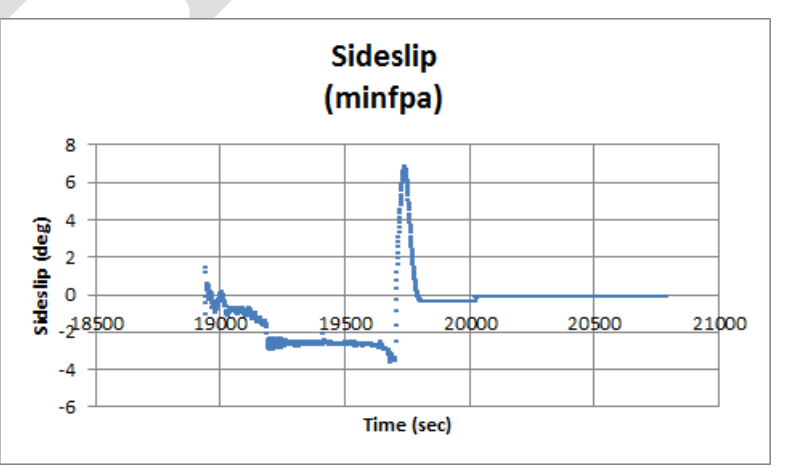

(b) Sideslip Angle

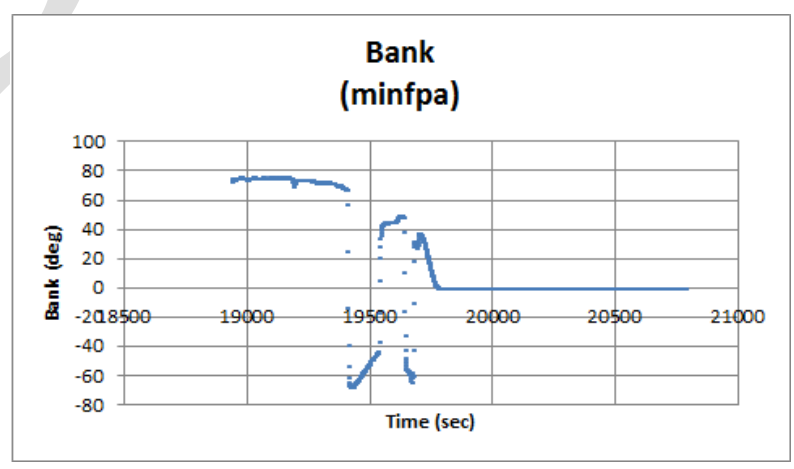

(c) Bank Angle

Figure 8. Attitude Plots for Failure Scenario Three (Min $\gamma_{\mathrm{EI}}$ )

8

American Institute of Aeronautics and Astronautics 


\section{Initial Pitch Rate Sensitivity Analysis}

The nominal initial conditions from Table 1 were used for the uncontrolled entries for the pitch rate sensitivity analysis. Initial pitch rates of 3, 4, and $5 \mathrm{deg} / \mathrm{s}$ were examined, in addition to the $10 \mathrm{deg} / \mathrm{s}$ for failure scenario 1 . The attitude plots are provided in Figure 9 - Figure 11.

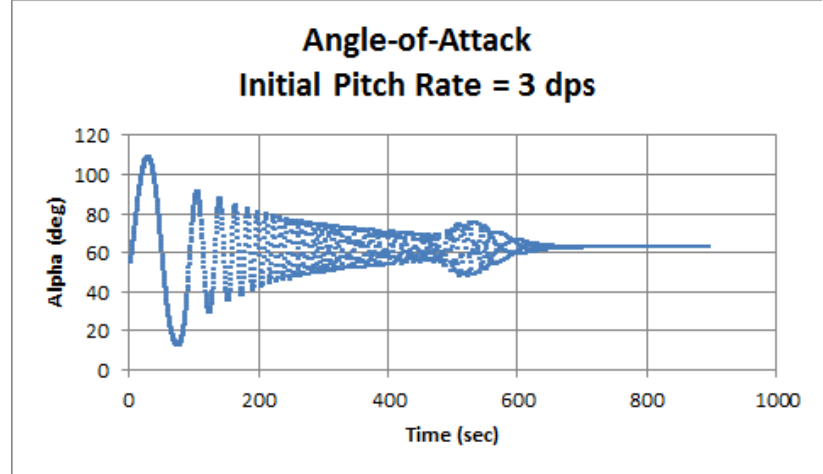

(a) Angle-of-Attack

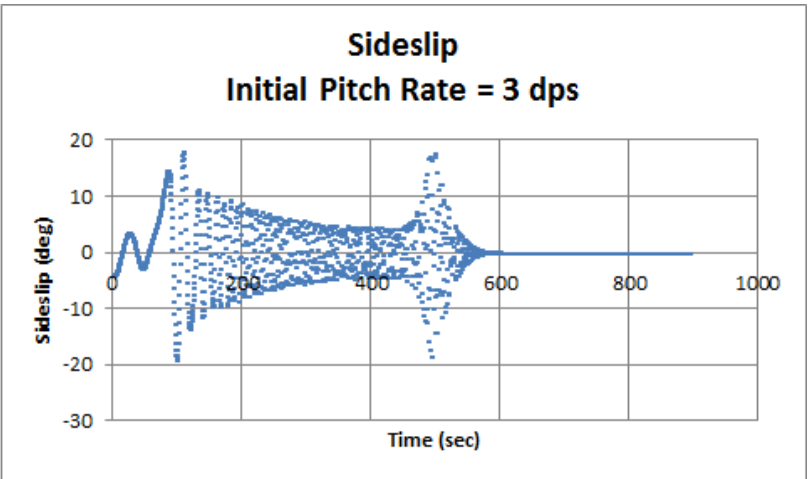

(b) Sideslip Angle

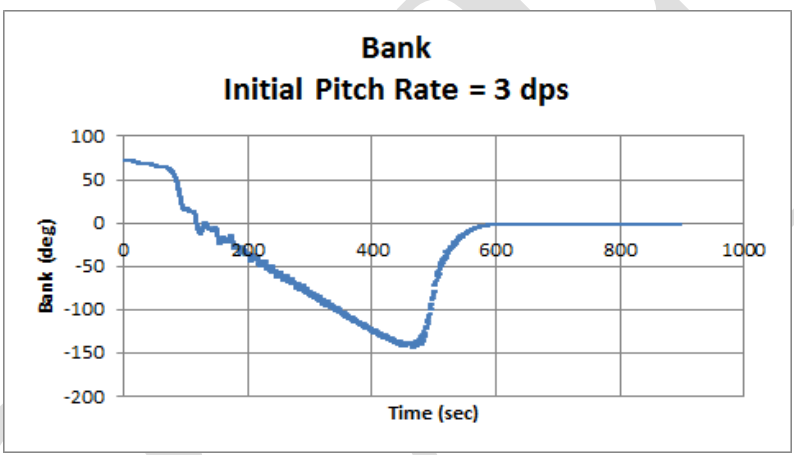

(c) Bank Angle

Figure 9. Attitude Plots for Initial Pitch Rate $=3 \mathrm{deg} / \mathrm{s}$

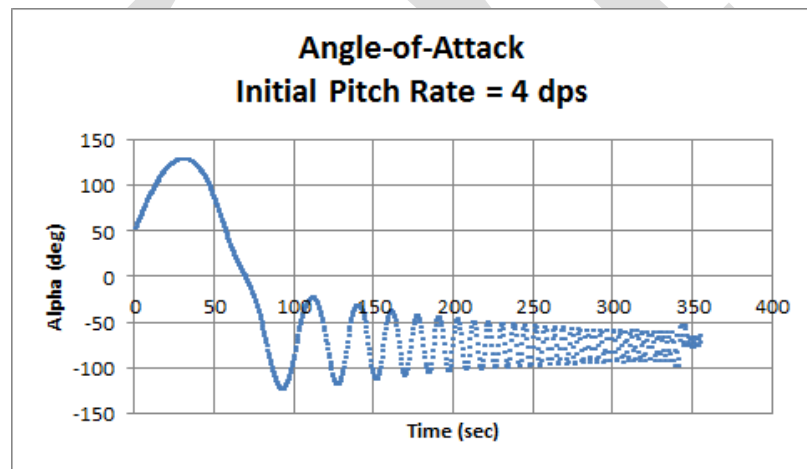

(a) Angle-of-Attack

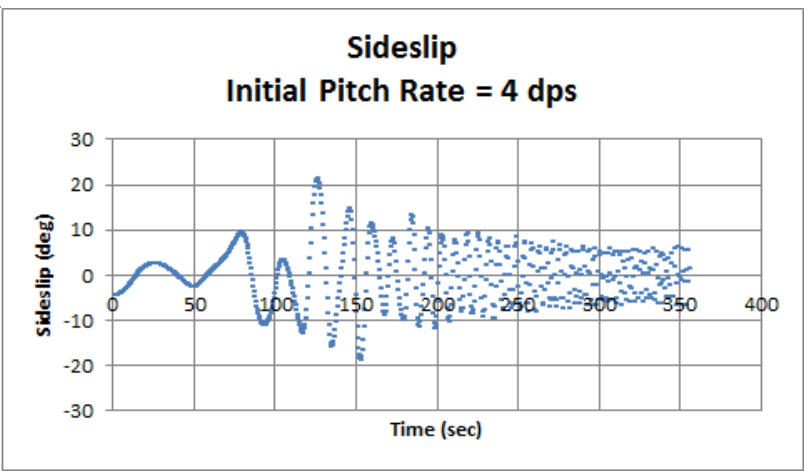

(b) Sideslip Angle 


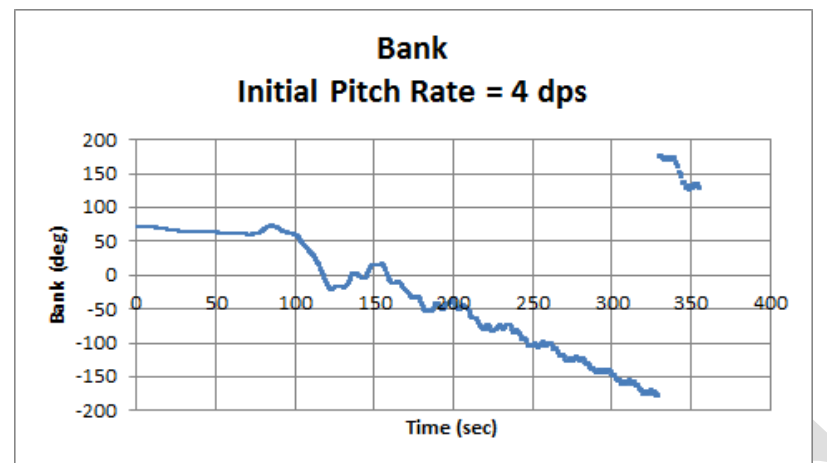

(c) Bank Angle

Figure 10. Attitude Plots for Initial Pitch Rate $=4 \mathrm{deg} / \mathrm{sec}$

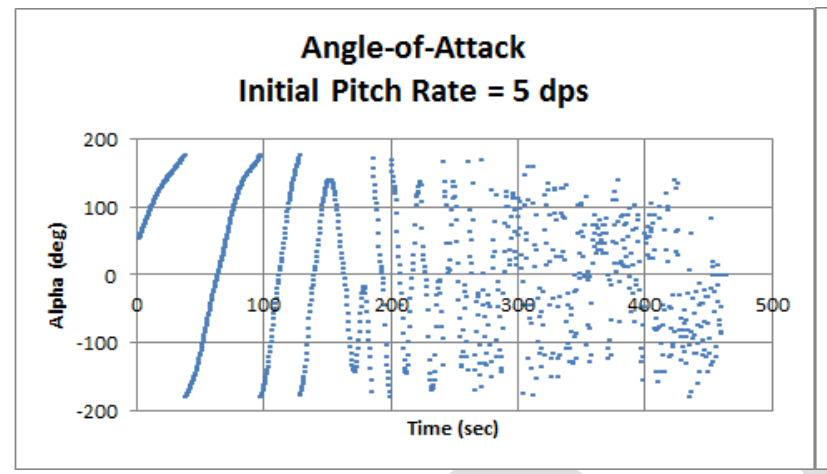

(a) Angle-of-Attack

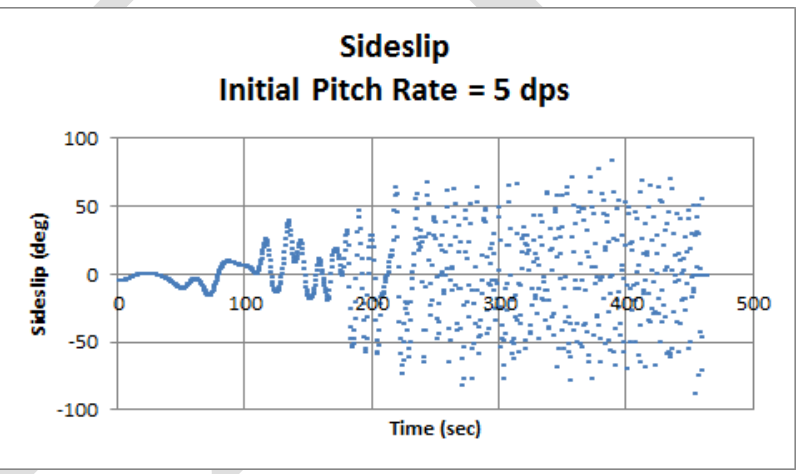

(b) Sideslip Angle

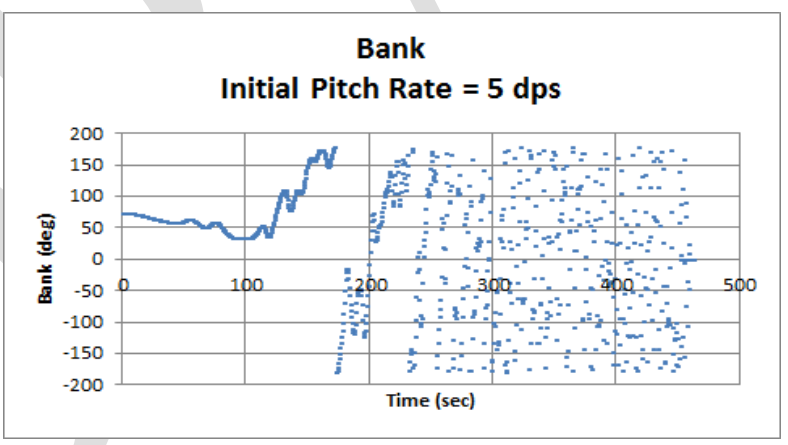

(c) Bank Angle

Figure 11. Attitude Plots for Initial Pitch Rate $=5 \mathrm{deg} / \mathrm{sec}$

The effects of the initial pitch rate on the vehicle re-orientation and breakup are given in Table 4.

Table 4. Effects of Initial Pitch Rate on Vehicle Re-orientation and Breakup

\begin{tabular}{|c|c|c|c|}
\hline $\begin{array}{c}\text { Initial Pitch Rate } \\
(\mathbf{d e g} / \mathbf{s})\end{array}$ & $\begin{array}{c}\text { Vehicle } \\
\text { Re-orientation }\end{array}$ & $\begin{array}{c}\text { FRSI Structure Failure } \\
\text { Altitude (km) }\end{array}$ & $\begin{array}{c}\text { Breakup Altitude } \\
(\mathbf{k m})\end{array}$ \\
\hline 3 & Trimmed nose-up & No breakup & No breakup \\
\hline 4 & Trimmed nose-down & 83.1 & 81.5 \\
\hline 5 & Remained tumbling & 70.5 & 68.6 \\
\hline 10 & Remained tumbling & 66.8 & 64.4 \\
\hline
\end{tabular}

10

American Institute of Aeronautics and Astronautics 
At an initial pitch rate of $4 \mathrm{deg} / \mathrm{s}$ or less, the vehicle's rotational motion damped out, and it re-oriented to one of the two trim attitudes. Whether it trimmed nose-up or nose-down depended on the initial attitude angle and attitude rate, and was therefore random. If it trimmed nose-up, the tiles would be facing the flow, and the vehicle would remain intact. If it trimmed nose-down, the FRSI would be under direct exposure to aeroheating, and the vehicle would break up. At an initial pitch rate of $5 \mathrm{deg} / \mathrm{s}$ or higher, the vehicle would remain tumbling, and the vehicle would break up. The conclusion of the sensitivity analysis is illustrated in Figure 12.

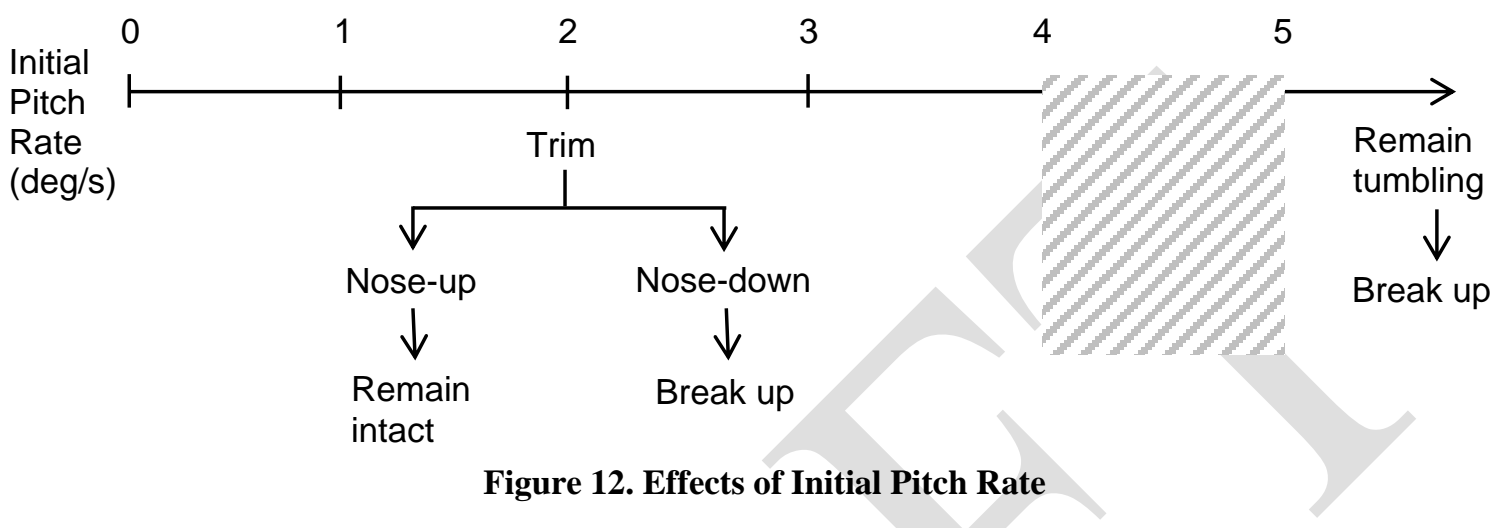

\section{Conclusion}

In an uncontrolled, otherwise nominal entry with initial pitch rate of $10 \mathrm{deg} / \mathrm{s}$, the mid-L/D lifting body was predicted to break up at an altitude of $64.4 \mathrm{~km}$. The surviving debris included heatshield tiles, FRSI fragments, and aluminum tank fragments. All the surviving debris landed in the Pacific Ocean.

The vehicle remained intact in the controlled steepest and shallowest entries. It maintained a trim, nose-up attitude with a small sideslip angle profile, such that the heatshield tiles protected the vehicle from aeroheating as designed.

The sensitivity analysis to determine the effects of initial pitch rate on the vehicle re-orientation and breakup was performed. The results indicated that the outcome of the mid-L/D lifting body in a nominal entry with loss of control depended on the initial attitude angle and attitude rate at EI. At an initial pitch rate of $4 \mathrm{deg} / \mathrm{s}$ or less, the vehicle will likely stabilize to one of its two trim attitudes. If it trimmed to the nose-up, heatshield-forward orientation, the vehicle will not break up. However, if it trimmed to the nose-down, FRSI-forward attitude, breakup will occur. At an initial pitch rate of $5 \mathrm{deg} / \mathrm{s}$ or greater, the vehicle will likely remain tumbling and will break up.

\section{References}

${ }^{1}$ Ling, L., "Simulation for Prediction of Entry Article Demise (SPEAD): an Analysis Tool for Spacecraft Safety Analysis and Ascent/Reentry Risk Assessment", $7^{\text {th }}$ IAASS Conference: Space Safety is No Accident, Friedrichshafen, Germany, 2014, pp. 415422.

${ }^{2}$ Milos, F., Scott, C., Del Papa, S., “Arcjet Testing and Thermal Model Development for Multilayer Felt Reusable Surface Insulation", AIAA paper.

${ }^{3}$ Noffz, G., Curry, R., "Summary of Aerothermal Test Results from the First Flight of the Pegasus Air-Launched Space Booster," NASA Dryden Flight Research Facility, Edwards, CA; AIAA paper, 1991. 